\title{
Defining a research agenda for youth sport specialisation in the USA: the AMSSM Youth Early Sport Specialization Summit
}

\author{
Stephanie A Kliethermes (1) ,' Stephen W Marshall, ${ }^{2}$ Cynthia R LaBella, ${ }^{3,4}$ \\ Andrew M Watson (1) ,' Joel S Brenner, ${ }^{5,6,7}$ Kyle B Nagle, ${ }^{8}$ Neeru Jayanthi (1) , ${ }^{9}$ \\ M Alison Brooks, ${ }^{1}$ Adam S Tenforde, ${ }^{10,11}$ Daniel C Herman (ㄷ, ${ }^{12,13}$ John P DiFiori, ${ }^{13}$ \\ Anthony I Beutler ${ }^{14,15}$
}

- Additional material is published online only. To view, please visit the journal online (http://dx.doi.org/10.1136/ bjsports-2020-102699).

For numbered affiliations see end of article.

Correspondence to Dr Stephanie A Kliethermes, Department of Orthopedics and Rehabilitation, University of Wisconsin-Madison, Madison, Wisconsin, USA;

kliethermes@ortho.wisc.edu

This article has been copublished in the British Journal of Sports Medicine and the Clinical Journal of Sport Medicine.

Accepted 8 September 2020

Check for updates

(C) Author(s) (or their employer(s)) 2020. No commercial re-use. See rights and permissions. Published by BMJ.

To cite: Kliethermes $S A$, Marshall SW, LaBella CR, et al. Br J Sports Med 2021:55:135-143.

\section{ABSTRACT}

Sport specialisation is becoming increasingly common among youth and adolescent athletes in the USA and many have raised concern about this trend. Although research on sport specialisation has grown significantly, numerous pressing questions remain pertaining to short-term and long-term effects of specialisation on the health and well-being of youth, including the increased risk of overuse injury and burnout. Many current elite athletes did not specialise at an early age. Methodological and study design limitations impact the quality of current literature, and researchers need to prioritise pressing research questions to promote safe and healthy youth sport participation. The American Medical Society for Sports Medicine hosted a Youth Early Sport Specialization Summit in April 2019 with the goal of synthesising and reviewing current scientific knowledge and developing a research agenda to guide future research in the field based on the identified gaps in knowledge. This statement provides a broad summary of the existing literature, gaps and limitations in current evidence and identifies key research priorities to help guide researchers conducting research on youth sport specialisation. Our goals are to help improve the quality and relevance of research on youth sport specialisation and to ultimately assure that opportunities for healthy and safe sport participation continue for all youth.

\section{INTRODUCTION}

Youth sport participation patterns in the USA have drastically changed over the past decade. The primary focus of youth sports has shifted from one of participation, fun and fitness to one increasingly centred on training and performance. In some communities and youth environments, opportunities for unstructured free play (eg, neighbourhood and backyard sports) have been reduced due to the demands of intensive sport teams training year-round. Numerous benefits, including physical and cognitive growth, have been associated with unstructured free play among youth. ${ }^{12}$ According to one study of nearly 1200 young athletes, there is a decreased risk of injury when children do not exceed a 2:1 ratio of number of weekly hours spent in organised sports to unstructured free play. ${ }^{3}$

Sport specialisation is typically defined as intense training in a single sport to the exclusion of all other sports. ${ }^{4-6}$ It is estimated that between $10 \%$ and $30 \%$ of youth athletes in the USA specialise in a single sport at a mean age of approximately $12-14 .^{7-9}$ One of the factors driving this specialisation trend may be the belief that starting intensive training at an early age is necessary for achieving elite levels in sport (eg, National or Olympic team, collegiate scholarship, professional sports contract). The available evidence, however, suggests that while specialisation at an early age may be advantageous for achieving elite status in a few individual sports where highly technical skills are honed through repetition beginning at a young age (eg, rhythmic gymnastics, diving and figure skating), ${ }^{10-12}$ early specialisation does not appear to be essential for achieving elite status in many other types of sports (eg, team sports such as soccer or baseball). ${ }^{9}$

Clinicians and researchers have expressed concern about the psychosocial and health effects of the escalating trend of sport specialisation among youth, particularly in early pubescent and prepubescent athletes under 12 years of age. ${ }^{13}$ There is concern that sport specialisation may result in an increased risk of overuse-type injury and early dropout from sports participation due to physical and emotional burnout. ${ }^{13}{ }^{14}$ Several professional medical organisations in the USA (including The American Society for Sports Medicine (AMSSM), the American Orthopedic Society for Sports Medicine (AOSSM), the American Academy of Pediatrics (AAP), and the National Athletic Trainers' Association (NATA)) have articulated concerns about youth sport specialisation and overuse injuries in young athletes. ${ }^{13-17}$ Some organisations have attempted to outline general recommendations for sports participation and young athlete development. Yet, substantial gaps exist in the scientific literature regarding the effect of specialisation on motor control development, sport performance, musculoskeletal injury risk, psychosocial outcomes, burnout and attrition, and on optimal strategies for youth athlete training and development in specific sports. These research gaps represent key impediments in the development of evidence-based clinical recommendations aimed at improving the health and safety of children and adolescents participating in sport.

The physical and psychological benefits of participation in youth sports are widely acknowledged; yet only $38 \%$ of children ages 6-12 participated regularly on a team or individual sport in 2018, 
representing an $8 \%$ decline from $2008 .{ }^{18}$ Participation in youth sports has been linked to increased physical activity in adulthood. ${ }^{1920}$ Sports have historically offered a fun, social and safe environment for youth. Unfortunately, according to the National Youth Sport Parent Survey, children quit most sports by age $11,{ }^{21}$ with girls dropping out of sports at a higher rate than boys. ${ }^{22} 23$ While the reasons for this are not fully elucidated, ${ }^{24}$ the trend towards youth sport specialisation at a young age is thought to be a contributing factor. This points to a larger public health issue associated with youth sport specialisation, given only $20 \%$ of adolescents currently meet the recommended physical activity guidelines of at least $60 \mathrm{~min}$ of moderate-to-vigorous physical activity each day. ${ }^{25}$ Based on current estimates for rates of youth sport specialisation, it has been suggested that up to 20 million young athletes may be highly specialised. ${ }^{26}$ Additionally, US healthcare costs, as a result of injuries attributable to youth sport specialisation, have been estimated to be between US $\$ 800$ million and US\$5.2 billion annually. ${ }^{26}$

Both physically inactive youth and those participating in excessive training load for sports cause reasons for concern. The US Department of Health and Human Services released the National Youth Sports Strategy in 2019, which aims to overcome barriers to youth sport participation and increase access across the USA. ${ }^{27}$ Sports provide an opportunity for youth to regularly engage in physical activity and to develop numerous positive habits that have the potential to extend into adulthood. Thus any barriers to sport participation are of great public health concern. On the other hand, many young athletes with ample access and numerous opportunities for sport participation may be pushed to participate in ways that may be harmful to their short-term and long-term health. These 'yin and yang' sports participation groups illustrate the public health concern to be addressed: what are the optimal implementation strategies to increase levels of healthy youth sports participation across all socioeconomic strata and athletic ability groups?

The AMSSM's Collaborative Research Network (CRN) hosted a research summit on Youth Early Sport Specialization in April 2019. The summit aimed to (1) synthesise and review current scientific knowledge in the field of youth athlete training and development as it relates to youth sport specialisation and (2) develop a research agenda for the USA to inform future research efforts in the field based on existing evidence and identified gaps in evidence. This research statement uses the assimilated knowledge from the summit to provide a broad overview of current gaps in knowledge, identify key research priorities and provide guidance for researchers pursuing studies in the space of youth sport specialisation. This statement fills a unique and important need in the area of youth sport as no consensus exists on how best to address the existing public health concerns of youth sport participation and how to advise young athletes, parents, coaches and sport administrators regarding the benefits and risks of youth sport specialisation in the USA.

\section{METHODS}

The Youth Early Sport Specialization Summit was held on 12 April 2019 in Houston, Texas, and was supported in part by a National Institute of Health R13 grant (1R13AR074878). The research summit panel was comprised of individuals and organisation representatives in North America with research and community-based expertise or interest in youth sport participation. Panellists included members of AMSSM and other key stakeholder medical organisations (including AOSSM, AAP and NATA) and non-medical influential leaders in youth sports promotion and governance. A complete list of summit speakers and organisational stakeholders is provided in online supplemental table 1 . The meeting was open to the public and broadly publicised in order to encourage attendance and engagement with clinicians, researchers, advocates and other interested groups.

Prior to the summit, three writing groups comprised of sports medicine physicians and individuals with expertise in research methodology and youth sport participation and specialisation in the USA were formed. Leaders of the AMSSM CRN identified and invited individuals with youth sport expertise within AMSSM who had published original research, reviews and position statements on this topic, had affiliations with external medical groups, and had demonstrated strong research experience to be members of the overall planning committee and individual writing groups. Members of this committee then completed a review process to identify individuals external to AMSSM who would enhance expertise, diversity and experience of the conference as panellists. These three writing groups conducted an extensive review of the literature assessing (1) the impact of sport specialisation on child and athlete performance and development, (2) the impact of youth sport specialisation on musculoskeletal injury risk and early discontinuation of sport and (3) organisational guidelines and recommendations for healthy and safe youth sport participation (online supplemental table 2). To ensure consistency among the three writing groups, co-chairs of each group discussed and agreed on common search strategies and work plans (eg, screening, eligibility review, abstraction) for their respective review topics. Specifically, the groups identified consistent terms and sources to be used during the systematic searches (online supplemental table 3), appropriate inclusion and exclusion criteria for each review, and eligible definitions of sport specialisation. To promote broad inclusion of potential research articles during the review process, an initial classification system for definitions of sport specialisation used in the sports medicine literature was developed based on writing group knowledge of commonly used definitions in the literature (table 1). To ensure consistency and cohesion among writing

\begin{tabular}{|c|c|}
\hline Construct(s) & Operational definition (reference to example studies) \\
\hline $\begin{array}{l}\text { Participates in one } \\
\text { sport only }\end{array}$ & $\begin{array}{l}\text { Participation in a single sport (specialised) versus } \\
\text { multisport participation (not-specialised). }{ }^{3347} \\
\text { - Exclusive participation in main sportt }{ }^{494}\end{array}$ \\
\hline Chose to be unisport & $\begin{array}{l}\text { Quit other sports to focus on main sport } \\
\text { Participation in primary sport to the exclusion of other } \\
\text { sports at or before } 12 \text { years old }\end{array}$ \\
\hline $\begin{array}{l}\text { Year-round } \\
\text { participation }\end{array}$ & $\begin{array}{l}\text { Train or participate in primary sport more than } 8 \text { months } \\
\text { out of year }\end{array}$ \\
\hline Multiple-item scales & $\begin{array}{l}\text { Jayanthi 3-item scale }{ }^{353} \text { : } \\
\text { 1. Primary sport more important than others } \\
\text { 2. Quit other sports to focus on one sport } \\
\text { 3. Train or participate in primary sport more than } 8 \\
\text { months out of year } \\
\text { Jayanthi } 6 \text {-item scale }{ }^{54} 55 \\
\text { 1. Train more than } 75 \% \text { time in primary sport } \\
\text { 2. Train to improve skill and miss time with friends as } \\
\text { a result } \\
\text { 3. Regularly travel out of state for primary sport } \\
\text { 4. Quit other sports to focus on } 1 \text { sport } \\
\text { 5. Primary sport more important than others } \\
\text { 6. Train or participate in primary sport more than } 8 \\
\text { months out of year }\end{array}$ \\
\hline
\end{tabular}




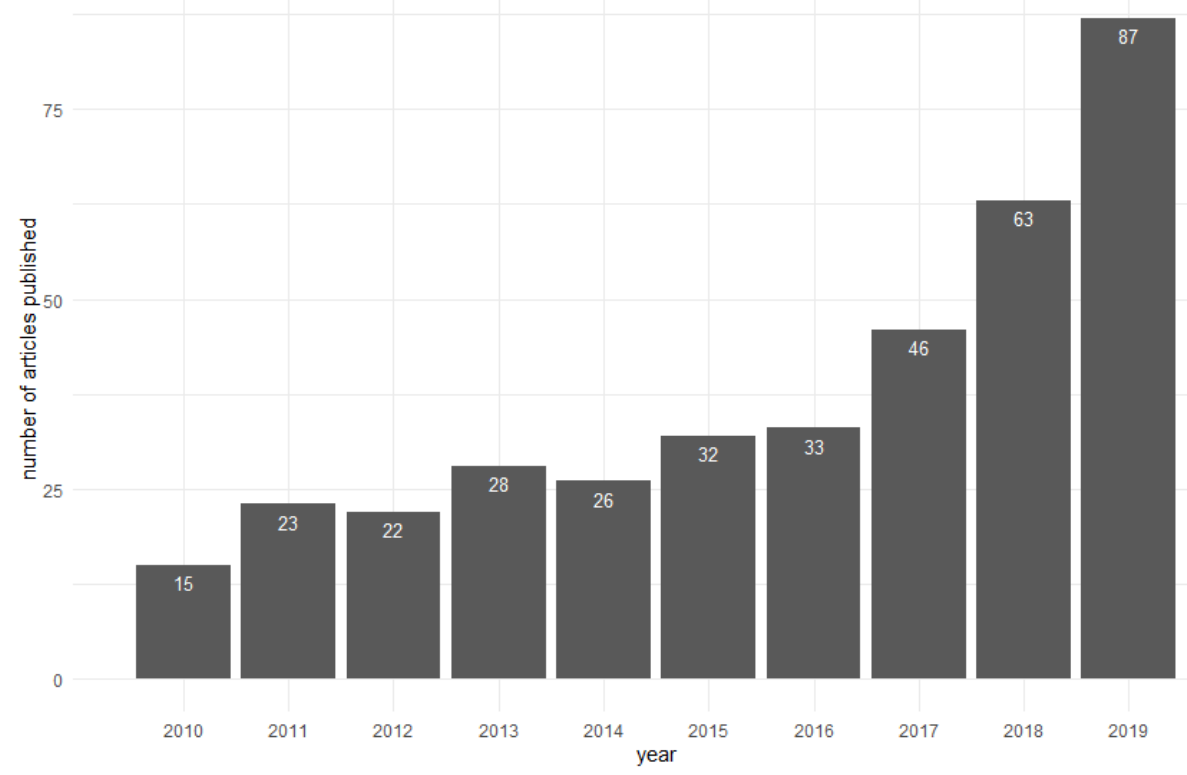

Figure 1 Number of articles retrieved from PubMed using term 'sport specialisation' by year of publication, 2010-2019.

groups' search strategy, co-chairs of each writing group met regularly to refine or add constructs as necessary. The results of the reviews were presented during the summit and used to facilitate interactions and solution-oriented discussions among key stakeholders. The reviews and important conclusions from the summit serve as the basis for the development of this evidencebased research agenda. Although the reviews were not restricted to research conducted in the USA, the intent was to develop research priorities focused on sport specialisation within the USA. Members of the summit's writing groups all had the opportunity to provide input towards the development of this research agenda prior to, during and after the research summit.

\section{MAIN FINDINGS}

\section{Current evidence}

Published research on sport specialisation continues to grow, especially over the past 3 years. A naïve PubMed search for the term 'sport specialisation' identified 166 articles published prior to 2010. Search results increased steadily over the past decade with $n=87$ publications on this topic in 2019 alone (figure 1). The available evidence has identified several themes.

Impact of sport specialisation on child and athlete performance and development

A growing body of the literature suggests youth sport specialisation is not a necessary pathway to achieve elite (D1 collegiate, professional, national, international) performance in most sports. ${ }^{9}$ Youth who specialise early and those who do not specialise until mid adolescence both achieve elite performance outcomes. The exception may be women's gymnastics or figure skating, ${ }^{10-12}$ where peak performance often occurs before puberty, so early specialisation is usually necessary in order to reach elite levels. However, research remains limited for these sports. For all other sports studied, elite athletes tend to specialise later than their non-elite or semielite peers at approximately 14-15 years compared with less than 12 years. Additionally, youth sport specialisation has not been shown to improve task-related performance outcomes (eg, neuromuscular control, standing broad jump, anterior reach, etc.) throughout childhood and adolescence. ${ }^{9}$

Impact of youth sport specialisation on musculoskeletal injury risk and early discontinuation of sport

Prior to 2019, 14 research studies assessed the relationship between youth sport specialisation and injury outcomes, primarily overuse injury.(Marshall SW, Herzog MM, Labella C, et al. Effects of youth sport specialization on injury and physical activity: A systematic review following the 2019 Youth Early Sport Specialization Summit. Unpublished manuscript in preparation.) These associations between youth sport specialisation and injury risk have been shown to persist even after controlling for training load (but only 3 of the 14 studies controlled for training load). The question of whether sport specialisation may increase risk for overuse injury independent of training load (eg, volume and intensity of all organised training, practice and competition sessions) remains a largely unexamined research topic. The lack of evidence raises concerns about the trend towards sport specialisation at an increasingly early age.

Organisational guidelines and recommendations for healthy and safe youth sport participation

Numerous medical organisations and sport governing bodies have published recommendations to promote healthy and safe youth sport participation, including guidelines addressing sport specialisation.(Herman DC, Nelson V, Montalvo A, et al. Current Health Organization Guidelines Relevant to Youth Sport Specialization: A Systematic Review following the American Medical Society for Sports Medicine (AMSSM) Collaborative Research Network's 2019 Youth Early Sport Specialization Summit. Unpublished manuscript in preparation),(Tenforde A, Montalvo A, et al. Current Organizational Recommendations Regarding Youth Sport Participation: A Systematic Synthesis Following the American Medical Society for Sports Medicine (AMSSM) Collaborative Research Network's 2019 Youth Early Sport Specialization Summit. Unpublished manuscript in preparation.) Unfortunately, published recommendations tend to be 
Table 2 Summary of systematic reviews of current evidence through 2018

\begin{tabular}{|c|c|c|c|c|}
\hline \multirow[b]{2}{*}{ Outcomes and topics } & \multicolumn{4}{|l|}{ Study design } \\
\hline & Cross-sectional* & Prospective & Case-control & Mixed $t$ \\
\hline \multicolumn{5}{|c|}{ Writing group 1: Impact of sport specialisation on child and athlete performance and development } \\
\hline Career performance & 15 & 0 & 0 & \\
\hline Task performance & 7 & 0 & 0 & \\
\hline Sport-specific skill performance & 0 & 0 & 0 & \\
\hline \multicolumn{5}{|c|}{ Writing group 2: Impact of youth sport specialisation on musculoskeletal injury risk and early discontinuation of sport } \\
\hline Injury & 9 & 4 & 1 & \\
\hline Physical activity, sport participation & 6 & 1 & 0 & \\
\hline Biomechanics & 1 & 0 & 0 & \\
\hline Subclinical abnormalities identified via imaging & 1 & 1 & 0 & \\
\hline \multicolumn{5}{|c|}{ Writing group 3: Organisational guidelines and recommendations for healthy and safe youth sport participation } \\
\hline Psychological development, approach & & & & 4 \\
\hline Physical development, load & & & & 8 \\
\hline Facilities and resources & & & & 6 \\
\hline Specialisation & & & & 8 \\
\hline
\end{tabular}

*Studies involving historical survey recall as well as studies assessing prevalent attributes in a cohort are classified as cross-sectional.

tMixed=number of associations or organisations with published statements based on a combination of evidence-based findings and expert opinion.

based both on expert opinion and existing evidence (table 2). Most medical organisations with published guidelines agree that specialisation should be delayed until after puberty (late adolescence, $\sim 15$ or 16 years of age $)^{28}$ but the expert guidelines do not consistently define the appropriate age for specialisation. Instead, the organisations promote sport sampling in the prepubertal developmental years, with the notion that children should not participate in multiple sports during the same season. The AAP, AMSSM and AOSSM all include figure skating and gymnastics as potential exceptions to this guideline, but specialisation research focused on these sports remains scarce. ${ }^{10-12}$ All published position statements from the medical organisations expressed concern regarding the potential psychosocial risks of specialisation, including 'burn-out', despite limited research evaluating potential associations. Organisations have identified additional focus areas for healthy and safe sport participation including appropriate approaches for psychological development and physical development-including training load and the need for quality facilities and resources. Finally, the various guidelines make extensive use of medical terminology and are not always presented in a manner conducive to effective implementation by coaches and administrators.

\section{Research gaps and limitations of current evidence Prospective research}

We identified numerous research gaps during both the literature review process and at the research summit. Most notably, we found no population-based prospective studies that follow youth throughout their organised sport career. To date, most study designs have been retrospective recall or cross-sectional (table 2), limiting the ability of investigators to identify causal relationships between youth sport specialisation and either positive or negative health and performance outcomes. Potential reasons for the lack of prospective studies on youth athletes include the intensive resources required to follow youth for most of their developmental years as well as the difficulty in prospectively operationalising the multiple sport pathways and opportunities for youth athletes.

\section{Sport-specific research}

In addition, limited information is available regarding potential sport-specific factors that are predictive of negative or positive effects of youth sport specialisation and whether these factors differ by sex. For example, the role of family and personal psychosocial mediators, such as parental versus youth desire and drive to focus on and participate competitively in one sport, remain relatively unexplored. While data on such important mediators are critical to developing effective guidelines and implementing successful clinician-led interventions, we identified few studies addressing this topic. ${ }^{29-31}$ Similarly, the effects of specialisation on outcomes of interest have been hypothesised to differ depending on the sport. Again, few research studies have assessed the role of sport type on potential associations between youth sport specialisation and health or performance outcomes including psychosocial measures and dropout from sport.

\section{Performance and sport-specific skill research}

Studies demonstrate that both youth who specialise early in a sport and those who participate in multiple sports through mid adolescence can successfully obtain elite performance in a wide variety of sports. Unfortunately, the constructs and rationale that would explain why both competing pathways (multisport participation vs single-sport specialisation) can lead to elite success have yet to be elucidated. For example, athletes participating in multiple sports may simply have better physical conditioning and superior motor learning and neuromuscular integrative capacity relative to their specialised peers and thus do not need to focus on a single sport year-round to achieve performance success at the elite level. Alternatively, a child's natural athleticism may promote both multiple sport participation and long-term success as a result of early success in multiple sports. It may also be that youth who sample multiple sports have a greater opportunity to find the sport best suited for their individual potential and skillset. Available research has not demonstrated a benefit in fitness or gross motor ability outcomes for athletes who specialise compared with those who do not, ${ }^{32}{ }^{33}$ but more research is needed for a consensus to be reached. It is possible 
that youth who are more proficient in fitness and coordination tests may be more likely to participate in a variety of sports at young ages. Additionally, talented athletes may be attracted to and encouraged to participate in multiple sports for longer because they experience success in all of these sports or because coaches may desire their contributions on numerous teams.

Team ball sports may also benefit from a crossover effect where training in one sport (eg, soccer) can improve general skills and performance in all team ball sports due to transfer of skills such as pattern recognition and anticipation, decision-making, and movement adaptability and automaticity. ${ }^{34}$ However, no longitudinal studies exist assessing the potential association between youth sport specialisation and development of sport-specific skills. It remains unknown whether the widespread belief that specialising in a sport at a young age can lead to increased sport-specific skill in some sports is accurate, or conversely, whether sampling multiple sports leads to a cross-over effect in skill development.

\section{Need for further research}

Study design considerations

Given these research gaps and limitations, there is a need for research assessing the sport selection process that longitudinally assesses factors influencing sport selection or specialisation in a population of young athletes. Such studies should ideally span the maturation phase from the preadolescent phase to adulthood and include not only measurement of long-term athlete development and performance outcome measures, but also physical and mental health. There is also a need for prospective sport-specific studies, with measurable outcomes pertinent to those particular sports, that follow youth for the entirety of their athletic careers-including through young adulthood. While such studies have been conducted in the general population (eg, the National Longitudinal Study of Adolescent to Adult Health (Add Health), ${ }^{35}$ a similar approach in studying young athletes is lacking).

\section{Role of training load}

Future studies, particularly studies addressing injury risks, should also account for the complex interaction of an athlete's training load (eg, volume and intensity of all organised training, practice and competition sessions) in combination with youth sport specialisation. Accounting for training load is important when assessing whether youth sport specialisation is an independent risk factor for outcomes such as overuse injury. Only three studies to date have used analytical observational study designs when assessing injury risk and controlled for training load. ${ }^{3} 3637$ Future studies need to build on this foundation and should ensure that both youth sport specialisation and training load are independently assessed, in order to avoid confounding effects of specialisation by changes in training load. This includes not just increases in sport-specific practice and competition, but also shifts to more repetitive training of specific tasks, such as repetitive overtraining of pitching by youth baseball players. The role of showcases (ie, events specifically designed to allow athletes to showcase their talent to coaches and recruiters) and private coaches in promoting potentially harmful repetitive training is largely understudied.

\section{Conceptual and operational definition}

Methodologic gaps and limitations were also identified during the literature review process. Several different definitions of sport specialisation exist in the literature (table 1), and these definitions lead to athletes being classified differently (and at times incorrectly) depending on the definition used. ${ }^{38} \mathrm{~A}$ single validated, reliable definition and measure for youth sport specialisation has yet to be established, and valid measures of health outcomes of interest (specifically overuse injury) do not exist. This hampers the ability of researchers to accurately measure the effects of youth sport specialisation on short-term and long-term athlete health and well-being. ${ }^{39}$ This also greatly limits the ability to compare studies across populations and prevents effective pooling of data for possible meta-analyses. There is a pressing need for a validated, reliable and consistent instrument for measuring youth sport specialisation.

\section{Implementation of evidence}

Lastly, few studies have been conducted to assess the potential impact of interventions aimed at mitigating the negative effects of youth sport specialisation. Evaluation of promising interventional approaches that apply evidence-based recommendations to quantifiable health outcomes is lacking. Developing evidence-based recommendations requires identification of appropriate efficacy measures and research assessing the best implementation strategies of the recommendations for a given sport. Dissemination and implementation (D\&I) research is an emerging field of study that aims to assess adoption, implementation and sustainability of scientific evidence in various community or clinical settings. D\&I principles should be considered when developing and evaluating implementation strategies as research in this area is necessarily contextual and complex.

\section{RESEARCH PRIORITIES}

We propose the following six substantive and methodological research priorities based on the research limitations and gaps in knowledge (table 3).

Conduct methodological studies to develop consistent, valid and reliable measures and definitions of youth sport specialization and health outcomes (e.g. overuse injury) Rationale: Methodological studies can help to improve metrics for the assessment of youth sport specialisation and youth sport specialization-related outcomes. Given the numerous existing definitions of youth sport specialisation and documented limitations, there is a strong need for researchers to establish methods that provide valid, consistent and reliable ways to measure youth sport specialisation in order to quantify exposure. Ideally, these measures should be applied across both sexes, and a variety of sports, ages or age groups, and settings (eg, youth leagues or clubs, high school, collegiate, etc.); however, methodological studies are also needed to assess the need for incorporating sport-specific items for measuring youth early sport specialisation that are unique to the demands of that sport. Additionally, developing a standard definition and welldefined measurements of youth sport specialisation and related outcomes will facilitate improved future research quality and the eventual synthesis of research by systematic reviews and meta-analyses. Consistent and reliable assessment of health outcomes commonly associated with youth 


\begin{tabular}{ll}
\hline Table 3 & Youth sport specialisation research priorities \\
\hline Priority & Description \\
\hline 1 & $\begin{array}{l}\text { Conduct methodological studies to develop consistent, valid and reliable measures and definitions of youth sport specialisation and health outcomes (eg, overuse } \\
\text { injury) }\end{array}$ \\
\hline 2 & $\begin{array}{l}\text { Conduct prospective sport-specific studies of child athletic development and performance that address the effect of youth sport specialisation on achieved level of } \\
\text { athletic performance and sport-specific skill development, while controlling for the role that training load plays as a potential confounding, mediating or modifying } \\
\text { factor }\end{array}$ \\
\hline 3 & $\begin{array}{l}\text { Measure the impact of youth sport specialisation on psychosocial outcomes including burnout, self-confidence, quality of life, self-esteem, depression and anxiety } \\
\text { discontinuation of sport or both. Studies should be rigorous qualitative studies on reasons youth select different developmental pathways to elite athlete status }\end{array}$ \\
\hline 5 & $\begin{array}{l}\text { Study injury risk and other physical health outcomes (both positive and negative) of youth sport specialisation, with emphasis on sex-specific and sport-specific } \\
\text { prospective studies that measure both training load and sport specialisation } \\
\text { Conduct dissemination and implementation research to assess the impact of current guidelines and strategies addressing youth sport specialisation }\end{array}$ \\
\hline 6 &
\end{tabular}

sport specialisation are similarly necessary. This priority is of primary importance so that future contributions to literature minimise the methodological limitations of current research.

\section{Conduct prospective sport-specific studies of child athletic development and performance that address the effect of youth sport specialisation on achieved level of athletic performance and sport-specific skill development, while controlling for the role that training load plays as a potential confounding, mediating, or modifying factor}

Rationale: Prospective, sport-specific research is needed to better understand the associations between youth sport specialisation and performance outcomes while eliminating recall bias. While it has been established that youth sport specialisation is not required to achieve elite status as an adult, the role of youth sport specialisation in increasing an athlete's long-term athletic potential through enhanced skill development is unknown. In certain sports (eg, gymnastics, diving, figure skating, etc.) some data suggest (based on small sample sizes and retrospective studies) early, focused sport-specific skill-development might influence success at the elite level for a select group of athletes who can avoid injury and the psychosocial pressure related to performance outcomes. Unlike many youth sports, peak performance in these 'artistic' sports arguably occurs before completion of puberty; thus, starting at a young age may be necessary because success is dependent on perfecting highly technical skills through continuous repetition. However, more research is needed to tease out the unique role of specialisation for these sports compared with other youth sports where peak performance occurs later. Moreover, the role of training load (eg, volume and intensity of all organised training, practice and competition sessions) in the relationship between youth sport specialisation and performance has not been elucidated; recall bias is a limitation in retrospective study designs. Knowledge of appropriate training load is essential to fully understand the potential benefits and risks of youth sport specialisation on skill-development and continued participation in sports and physical activity. These findings may be especially important for those sports where peak performance is thought to occur at a young age.

\section{Measure the impact of youth sport specialisation on} psychosocial outcomes including burnout, self-confidence, quality of life, self-esteem, depression and anxiety

Rationale: Prior position statements have suggested that youth sport specialisation in childhood may lead to increased stress and burnout. Current evidence is limited to observational cross-sectional studies with small sample sizes. Despite the widespread concern about psychological impacts of sport specialisation on youth athletes, there is a need for larger prospective studies to better understand the relationship between specialisation with both positive and negative psychosocial outcomes. In particular, there is little data exploring long-term psychological or health consequences of youth sport specialisation. ${ }^{40}$ Future studies should also address potential sex-specific differences when assessing these relationships. Importantly, methodological research is needed for the development of a validated tool(s) to measure psychological health in youth athletes. Recently, the usefulness and validity of a widely used tool for measuring athlete burnout has been questioned due to inconsistent psychometric properties. ${ }^{41}$

Conduct prospective cohort assessments of youth sport participation pathways (specialisation vs multisport developmental pathways) to attainment of elite status, discontinuation of sport or both. Studies should be rigorous mixed methods studies on reasons youth select different developmental pathways to elite athlete status

Rationale: Prospective research on youth athlete development pathways is necessary to better understand if success in achieving elite status is more likely by (1) multisport athletes because they are gifted with better overall athletic skills or because they are exposed to a variety of sports and movement patterns or (2) youth sport specialisation for a specific subset of youth, especially youth who show a strong propensity and desire to participate in one sport. Priority should be placed on the design and implementation of sport-specific prospective cohort studies assessing multiple outcomes including lifelong physical activity, enjoyment of sport, development of sport skills and eventual career performance outcomes (see Research Priority \#1) among specialised and non-specialised athletes. Using mixed methods approaches will provide additional and needed insight into reasons for participation in the different athlete development pathways and the role of each pathway in discontinuing sport, premature or otherwise.

Study injury risk and other physical health outcomes (both positive and negative) of youth sport specialisation, with emphasis on sex- and sport-specific prospective studies that measure both training load and sport specialisation Rationale: Several studies have established an association between youth sport specialisation and musculoskeletal 
injury, especially overuse injury. Many of these studies have been limited in their ability to establish causality between sport specialisation and injury risk due to their descriptive (eg, cross-sectional or historical survey recall) designs (table 2), and lack of adequate power to evaluate potential sex and sport differences. Additionally, very few studies consider the role of training load in these associations. Future research needs to tease out the independent contributions of youth sport specialisation and training load on injury risk. Other health outcomes of interest include emotional well-being, sleep, cardiovascular health, bone density and risk of illness.

\section{Conduct dissemination and implementation research to assess the impact of current guidelines and strategies addressing youth sport specialisation}

Rationale: Although numerous guidelines exist, many rely heavily on expert opinion because of the absence of evidencebased guidance. Current evidence-based guidelines are not being effectively communicated to key stakeholders including young athletes, parents, coaches and sport administrators. With the expansion of evidence-based guidelines, research focusing on the development, dissemination, adoption, and implementation of strategies to address youth sport specialisation and athlete development are necessary to effectively translate research findings into the community. Research should be conducted regarding the efficacy of evidencebased recommendations and how best to implement these recommendations into a community setting. Effective D\&I research will include all relevant stakeholders at all stages of the research process and should investigate potential social, economic and geo-political contexts and complexities. Finally, D\&I research on guidelines and strategies addressing youth sport specialisation should be conducted using appropriate D\&I methodology and frameworks.

\section{SUMMARY OF RECOMMENDATIONS AND LIMITATIONS}

Research related to youth sport specialisation continues to grow as the trend toward early specialisation increases in youth sport. Youth sports is now a US $\$ 15.3$ billion industry in the USA, ${ }^{42}$ fueled by organisations that do not always align with the long-term health and development of participating youth. Youth sport is rife with organisations that fail to address the barriers preventing participation by many young athletes. Despite the increase in research on youth sport specialisation over the past decade, this is still a relatively young area of study and knowledge and beliefs about the potential impact of youth sport specialisation among parents, coaches and athletes is mixed. ${ }^{29} 3043$ Current evidence suffers from numerous methodological limitations and the research field needs direction. Research questions and designs used to study this topic must become more focused and sophisticated in order to better understand both the risks and benefits associated with youth sport specialisation in its specific context. To enhance the quality and rigour of methodological research in this field, researchers should adhere to guidelines proposed by the Enhancing the QUAlity and Transparency Of Health Research network ${ }^{44}$ for various study designs as well as pertinent consensus statements on methodological considerations unique to sports medicine. ${ }^{45}$ In order for professional medical organisations to provide guidelines that are appropriate and effective, evidence supporting the merit and need for such policies is essential. Moreover, research is necessary to accurately define the public health concerns associated with youth sport specialisation and participation more broadly, and to explore if the numerous noted shortand long-term benefits of youth sport persist in the context of early specialisation.

The research priorities identified in this research agenda are not mutually exclusive. Multiple priorities can and should be addressed in a single study. Research studies are needed at all stages of this translational research topic. Methodological improvements to measures of youth sport specialisation and related outcomes are essential so that the collective body of evidence can be compared uniformly. Prospective, sport-specific studies are needed so researchers can more fully understand the merits and risks of differing pathways of youth sport participation. Lastly, the effectiveness of existing and future guidelines and recommendations for healthy and safe youth sport participation must be continuously examined and rigorously assessed.

There were some limitations in the development of this research agenda and key research priorities. Although we considered international research articles in our synthesis of evidence, we did not include international experts in this process primarily due to resource constraints. This resulted in a research agenda that is focused primarily on youth sport specialisation research needs in the USA. We also did not register our systematic reviews on the PROSPERO international prospective register of systematic reviews. Moreover, in organising our writing groups and summit panel, we attempted to maintain gender balance, include stakeholders from multiple areas of youth sport, and ensure representation of underrepresented minorities; however, we did not fully achieve this parity due to conflicting schedules and limited individuals with known expertise in certain areas of youth sport specialisation. This may have resulted in the development of research priorities that are insufficient for all key stakeholders. Finally, we achieved consensus on key research priorities among all members of the planning committee; however, a more rigorous approach would have been to conduct a formal Delphi process involving key stakeholders and international leaders in the process.

We recognise the current funding landscape presents many challenges that make it difficult to address some of the longerterm research priorities. To that end, it is vital that multiple stakeholders, including funders, are knowledgeable of the current and future public health implications associated with the current youth sport environment and find ways to work together to achieve these priorities. The National Youth Sport Strategy, ${ }^{27}$ an important first step in promoting a centralised vision for change in youth sport, is geared towards policy makers and key decision makers in youth sport to help ensure all youth have an opportunity to participate safely and reap the numerous benefits of sport. Among other benefits, physical activity is associated with improved cardiovascular health and body composition in adults, thus establishing a physically active lifestyle through sport in youth may be vital in promoting long-term health outcomes in adulthood. ${ }^{46}$ The research community has an important complementary role in advancing the strategy's central aim of increasing youth sport participation opportunities-especially in communities with fewer resources. Due to the limitations in the available research, it is difficult to provide appropriate evidence-based guidelines and recommendations that can be easily translated to sports administrators, parents, coaches, youth organisations and athletes about safe and healthy youth sport participation. Rigorous high-quality research not only provides the necessary foundation for promoting meaningful and healthy youth sport participation, it is essential for informing youth sport leaders on appropriate sport participation patterns that encourage lifelong physical activity and well-being. As the evidence regarding 
short-term and long-term effects of youth sport specialisation continues to grow, a similar commitment to rigorously studying and understanding the best approaches for D\&I must occur. The inclusion of parents, athletes, researchers, physicians, community leaders and policy-makers in this complex and challenging process will be instrumental to creating lasting and meaningful change for safe and healthy participation in youth sport.

\section{CONCLUSION}

The research priorities identified in this research agenda aim to improve the safety and long-term health impacts of youth sports participation and represent vital areas of focus for investigators in sports medicine as well as public and private funders in the USA. Research findings resulting from sustained progress on these priorities can contribute to high-quality evidencebased guidelines for youth sport participation that promote long-term health and development of young athletes. It is now important to extend these research recommendations globally, involving patient and public representatives, and international stakeholders, and to consider and plan for the complexities of implementation.

\section{Author affiliations \\ 'Department of Orthopedics and Rehabilitation, University of Wisconsin Madison School of Medicine and Public Health, Madison, Wisconsin, USA \\ ${ }^{2}$ Injury Prevention Research Center and Department of Epidemiology, University of North Carolina at Chapel Hill, Chapel Hill, North Carolina, USA \\ ${ }^{3}$ Department of Pediatrics, Northwestern University's Feinberg School of Medicine, Chicago, IL, USA \\ ${ }^{4}$ Division of Orthopedics and Sports Medicine, Ann \& Robert H Lurie Children's Hospital of Chicago, Chicago, Illinois, USA \\ ${ }^{5}$ Sports Medicine Program, Children's Hospital of The King's Daughters, Norfolk, Virginia, USA \\ ${ }^{6}$ Department of Pediatrics, Eastern Virginia Medical School, Norfolk, Virginia, USA ${ }^{7}$ Sports Medicine Division, Children's Specialty Group, PLLC, Norfolk, Virginia, USA ${ }^{8}$ Department of Pediatrics and Orthopedics and Rehabilitation, University of Washington School of Medicine; Seattle Children's Hospital, Seattle, Washington, USA \\ ${ }^{9}$ Departments of Orthopaedics and Family Medicine, Emory Sports Medicine Center; Emory University School of Medicine, Atlanta, Georgia, USA \\ ${ }^{10}$ Spaulding Rehabilitation Hospital, Boston, Massachusetts, USA \\ ${ }^{11}$ Department of Physical Medicine and Rehabilitation, Harvard Medical School, Boston, MA, USA \\ ${ }^{12}$ Orthopaedics and Rehabilitation, University of Florida, Gainesville, Florida, USA \\ ${ }^{13}$ Hospital for Special Surgery, New York, New York, USA \\ ${ }^{14}$ Musculoskeletal Clinical Program, Intermountain Health Care Inc, Salt Lake City, Utah, USA \\ ${ }^{15}$ Department of Family Medicine, Uniformed Services University of the Health Sciences, Bethesda, Maryland, USA}

Twitter Neeru Jayanthi @neerujayanthi, M Alison Brooks@DrABrooksUWisc and Adam S Tenforde @AdamTenfordeMD

Contributors All authors contributed to the conception or design of the work. SAK and AIB contributed to drafting the manuscript. All authors critically reviewed it and agreed on final version. All authors agree to be accountable for all aspects of the manuscript.

Funding Development of this research agenda was supported by the National Institute of Arthritis and Musculoskeletal and Skin Diseases of the National Institutes of Health under award number 1R13AR074878.

Competing interests JB reports personal fees from UpToDate, outside the submitted work. MAB reports grants from National Institute of Health, during the conduct of the study; other from American Academy of Pediatrics, other from American Medical Society for Sports Medicine, outside the submitted work.

Patient consent for publication Not required.

Provenance and peer review Not commissioned; externally peer reviewed.

Data availability statement There are no data in this work

Supplemental material This content has been supplied by the author(s). It has not been vetted by BMJ Publishing Group Limited (BMJ) and may not have been peer-reviewed. Any opinions or recommendations discussed are solely those of the author(s) and are not endorsed by BMJ. BMJ disclaims all liability and responsibility arising from any reliance placed on the content. Where the content includes any translated material, BMJ does not warrant the accuracy and reliability of the translations (including but not limited to local regulations, clinical guidelines, terminology, drug names and drug dosages), and is not responsible for any error and/or omissions arising from translation and adaptation or otherwise.

\section{ORCID iDs}

Stephanie A Kliethermes http://orcid.org/0000-0001-9756-7406

Andrew M Watson http://orcid.org/0000-0001-5122-2197

Neeru Jayanthi http://orcid.org/0000-0001-7900-962X

Daniel C Herman http://orcid.org/0000-0002-6646-2975

\section{REFERENCES}

1 Murray R, Ramstetter C, et al, Council on School Health. The crucial role of recess in school. Pediatrics 2013;131:183-8.

2 Yogman M, Garner A, Hutchinson J, et al. The power of play: a pediatric role in enhancing development in young children. Pediatrics 2018;142:e20182058.

3 Jayanthi NA, LaBella CR, Fischer D, et al. Sports-specialized intensive training and the risk of injury in young athletes: a clinical case-control study. Am I Sports Med 2015;43:794-801.

4 Jayanthi N, Pinkham C, Dugas L, et al. Sports specialization in young athletes: evidence-based recommendations. Sports Health 2013;5:251-7.

5 Malina RM. Early sport specialization: roots, effectiveness, risks. Curr Sports Med Rep 2010;9:364-71.

6 Myer GD, Jayanthi N, Difiori JP, et al. Sport specialization, part I: does early sports specialization increase negative outcomes and reduce the opportunity for success in young athletes? Sports Health 2015;7:437-42.

7 Bell DR, Post EG, Biese K, et al. Sport specialization and risk of overuse injuries: a systematic review with meta-analysis. Pediatrics 2018;142:e20180657.

8 Buckley PS, Bishop M, Kane P, et al. Early single-sport specialization: a survey of 3090 high school, collegiate, and professional athletes. Orthop I Sports Med 2017;5:2325967117703944.

9 Kliethermes SA, Nagle K, Côté J, et al. Impact of youth sports specialisation on career and task-specific athletic performance: a systematic review following the American medical Society for sports medicine (AMSSM) Collaborative research network's 2019 youth early sport specialisation Summit. Br J Sports Med 2020:54:221-30.

10 Hume PA, Hopkins WG, Robinson DM, et al. Predictors of attainment in rhythmic sportive gymnastics. J Sports Med Phys Fitness 1993;33:367-77.

11 Law MP, Côté J, Ericsson KA. Characteristics of expert development in rhythmic gymnastics: a retrospective study. Int I Sport Exerc Psychol 2007;5:82-103.

12 Starkes JL, Deakin JM, Allard F, et al. Deliberate practice in sports: What is it anyway. In: Ericsson $\mathrm{A}$, ed. The road to excellence: the acquisition of expert performance in the arts and sciences, sports, and games. New York: Psychology Press, 1996: 81-106.

13 Brenner JS, American Academy of Pediatrics Council on Sports Medicine and Fitness. Overuse injuries, overtraining, and burnout in child and adolescent athletes. Pediatrics 2007:119:1242-5.

14 DiFiori JP, Benjamin HJ, Brenner J, et al. Overuse injuries and burnout in youth sports: a position statement from the American medical Society for sports medicine. Clin J Sport Med 2014;24:3-20.

15 Bergeron MF, Mountjoy M, Armstrong N, et al. International Olympic Committee consensus statement on youth athletic development. Br I Sports Med 2015;49:843-51.

16 LaPrade RF, Agel J, Baker J, et al. AOSSM early sport specialization consensus statement. Orthop J Sports Med 2016;4:2325967116644241.

17 Valovich McLeod TC, Decoster LC, Loud KJ, et al. National athletic trainers association position statement: prevention of pediatric overuse injuries. J Athl Train 2011:46:206-20.

18 The Aspen Institute. State of play: trends and developments in youth sports. Washington, DC: The Aspen Insitute, 2019. https://assets.aspeninstitute.org/content/ uploads/2019/10/2019_SOP_National_Final.pdf

19 Kjønniksen L, Anderssen N, Wold B. Organized youth sport as a predictor of physical activity in adulthood. Scand J Med Sci Sports 2009;19:646-54.

20 Telama R, Yang $X$, Hirvensalo $M$, et al. Participation in organized youth sport as a predictor of adult physical activity: a 21-year longitudinal study. Pediatr Exerc Sci 2006;18:76-88.

21 The Aspen Institute. Survey: kids quit most sports by age 11. Available: https://www. aspenprojectplay.org/national-youth-sport-survey/1 [Accessed 8 May 2020].

22 Sabo D. Pt V. Part VI: entry into sports, dropping out of sports. in: go out and play: youth sports in America. East Meadow, NY: Women's Sports Foundation, 2008: 119-35. https://www.womenssportsfoundation.org

23 Zarrett N, Veliz PT, Sabo D. Keeping girls in the game: factors that influence sport participation. New York, NY: Women's Sports Foundation, 2020. https://www.wome nssportsfoundation.org/wp-content/uploads/2020/02/Keeping-Girls-in-the-GameFINAL-web.pdf

24 Witt PA, Dangi TB. Why children/youth drop out of sports. J Park Recreat Admi 2018:36:191-9. 
25 U.S. Department of health and human services office of disease prevention and health promotion. Washington, D.C: National Center for Health Statistics, 2010. https:// www.healthypeople.gov/

26 Bell DR, DiStefano L, Pandya NK, et al. The public health consequences of sport specialization. J Athl Train 2019;54:1013-20.

27 U.S. Department of health and human services. Washington, D.C. U.S: Department of Health and Human Services, 2019. https://health.gov/

28 Jayanthi NA, Post EG, Laury TC, et al. Health consequences of youth sport specialization. J Ath/ Train 2019;54:1040-9.

29 Bell DR, Post EG, Trigsted SM, et al. Parents' awareness and perceptions of sport specialization and injury prevention recommendations. Clin J Sport Med 2018. doi:10.1097/JSM.0000000000000648. [Epub ahead of print: 08 Aug 2018].

30 Brooks MA, Post EG, Trigsted SM, et al. Knowledge, attitudes, and beliefs of youth Club athletes toward sport specialization and sport participation. Orthop J Sports Med 2018;6:2325967118769836.

31 Patel T, Jayanthi N. Health-Related quality of life of specialized versus multi-sport young athletes: a qualitative evaluation. J Clin Sport Psychol 2018;12:448-66.

32 DiStefano LJ, Beltz EM, Root HJ, et al. Sport sampling is associated with improved landing technique in youth athletes. Sports Health 2018;10:160-8.

33 Fransen J, Pion J, Vandendriessche J, et al. Differences in physical fitness and gross motor coordination in boys aged $6-12$ years specializing in one versus sampling more than one sport. J Sports Sci 2012;30:379-86.

34 Abernethy B, Baker J, Côté J. Transfer of pattern recall skills may contribute to the development of sport expertise. App/ Cogn Psychol 2005;19:705-18.

35 Harris KM, Udry JR. National Longitudinal Study of Adolescent to Adult Health (Add Health), 1994-2008 [Public Use]. Carolina Population Center. University of North Carolina-Chapel Hill [distributor], Inter-university Consortium for Political and Social Research [distributor], 2018. https://doi.org/10.3886/ICPSR21600.v21

36 McGuine TA, Post EG, Hetzel SJ, et al. A prospective study on the effect of sport specialization on lower extremity injury rates in high school athletes. Am J Sports Med 2017;45:2706-12

37 Post EG, Trigsted SM, Riekena JW, et al. The association of sport specialization and training volume with injury history in youth athletes. Am J Sports Med 2017;45:1405-12.

38 Miller M, Malekian S, Burgess J, et al. Evaluating a commonly used tool for measuring sport specialization in young athletes. J Ath/ Train 2019;54:1083-8.

39 Jayanthi N, Kliethermes SA, Côté J. Youth sport specialisation: the need for an evidence-based definition. Br J Sports Med 2020;54:196-7.

40 Brenner JS, LaBotz M, Sugimoto D, et al. The psychosocial implications of sport specialization in pediatric athletes. J Ath/ Train 2019;54:1021-9.
41 Gerber M, Gustafsson H, Seelig H, et al. Usefulness of the athlete burnout questionnaire $(A B Q)$ as a screening tool for the detection of clinically relevant burnout symptoms among young elite athletes. Psychol Sport Exerc 2018:39:104-13

42 Gregory S. How kids' sports became a $\$ 15$ billion industry. Available: https://time. com/4913687/how-kids-sports-became-15-billion-industry/

43 Post EG, Trigsted SM, Schaefer DA, et al. Knowledge, attitudes, and beliefs of youth sports coaches regarding sport volume recommendations and sport specialization. J Strength Cond Res 2018. doi:10.1519/JSC.0000000000002529. [Epub ahead of print: 22 Feb 2018].

44 The Equator Network. Enhancing the quality and transparency of health research. Available: https://www.equator-network.org/ [Accessed 8 May 2020].

45 Bahr R, Clarsen B, Derman W, et al. International Olympic Committee consensus statement: methods for recording and reporting of epidemiological data on injury and illness in sport 2020 (including STROBE extension for sport injury and illness surveillance (STROBE-SIIS)). Br J Sports Med 2020;54:372-89.

46 U.S. Department of Health and Human Services. Physical activity quidelines for Americans. 2nd edn. Washington: D.C. US Department of Health and Human Services, 2018. https://health.gov

47 Beese ME, Joy E, Switzler CL, et al. Landing error scoring system differences between single-sport and multi-sport female high school-aged athletes. J Ath/ Train 2015;50:806-11.

48 Coutinho P, Mesquita I, Fonseca AM, et al. Expertise development in volleyball: the role of early sport activities and players' age and height. Kinesiology 2015:47:215-25

49 Güllich A. Many roads lead to Rome--developmental paths to Olympic gold in men's field hockey. Eur J Sport Sci 2014;14:763-71.

50 Black S, Black K, Dhawan A, et al. Pediatric sports specialization in elite ice hockey players. Sports Health 2019;11:64-8.

51 Bell DR, Lang PJ, Valovich McLeod TC, et al. Sport specialization is associated with injury history in youth soccer athletes. Athl Train Sports Health Care 2018;10:241-6.

52 Bell DR, Post EG, Trigsted SM, et al. Prevalence of sport specialization in high school athletics: a 1-year observational study. Am J Sports Med 2016;44:1469-74.

53 Post EG, Bell DR, Trigsted SM, et al. Association of competition volume, Club sports, and sport specialization with sex and lower extremity injury history in high school athletes. Sports Health 2017;9:518-23.

54 Jayanthi N, Pinkham C, Durazo-Arivu R, et al. The risks of sports specialization and rapid growth in young athletes. Clin J Sport Med 2011;21:157.

55 Miller MM, Trapp JL, Post EG, et al. The effects of specialization and sex on anterior Y-balance performance in high school athletes. Sports Health 2017;9:375-82. 